IN FOLIO 


\title{
Tolstoi o el arrepentimiento: una alegoría de la existencia
}

\author{
Por Raymundo Gomezcásseres ${ }^{1}$ \\ Universidad de Cartagena
}

\begin{abstract}
Estupiñán Mojica, Hernán. (2013). Tolstoi o el arrepentimiento. Sincelejo: Unión de Escritores de Sucre, 158p.
\end{abstract}

Sería pretencioso hacer un acercamiento amplio (por no decir total) a la novela Tolstoi o el arrepentimiento, de Hernán Estupiñán Mojica, ganadora de la primera convocatoria del Premio Internacional "Héctor Rojas Herazo", promovido por la Asociación de Escritores de Sucre. Espero que esa insalvable dificultad se vea satisfactoriamente compensada por las palabras que siguen. Ellas apenas aspiran a una breve y modesta comprensión de lo que considero son las líneas gruesas de la narración, la historia y el relato.

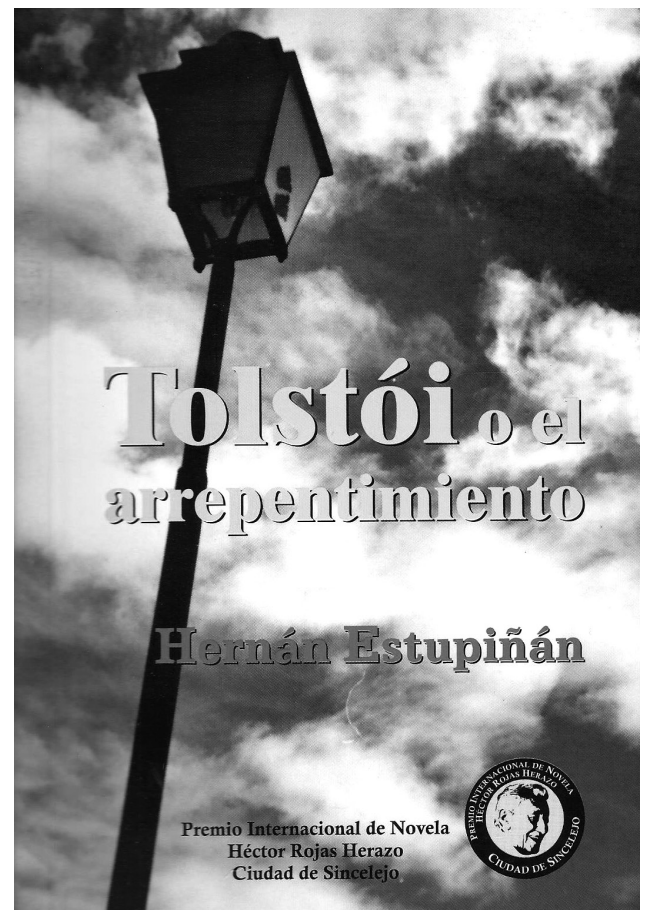

En términos puramente fácticos, Tolstoi o el arrepentimiento aspira a realizar la construcción literaria del itinerario cubierto por el autor de La guerra y la paz, entre Yasnaya Poliana y la estación ferroviaria de Astápovo, durante un tiempo impreciso, condensado cronológicamente en la probable duración de unos pocos días, que a la vez se dilatan e inflan en un lapso subjetivo construido a partir de una compleja malla de evocaciones (analepsis) y anticipaciones (prolepsis) narrativas que van configurando una historia. Historia

\footnotetext{
${ }^{1}$ Docente del Programa de Lingüística y Literatura de la Universidad de Cartagena. Director del Taller de Escritura Creativa "Coloquio" de la Universidad de Cartagena. Ha publicado las novelas Metástasis (1988) y Días así (1994). e-mail: holdencaulfield82@hotmail.com
} 
que a su vez resulta de entrecruzar y combinar las modalidades de la narración ulterior, la simultánea y la anterior. La narradora, pero más que narradora, protagonista de esa interiorización visibilizada en el relato, es Sasha (o Alexandra, tal es su nombre de pila), una de las hijas de León Tolstoi con Sofía Andreievna, su esposa.

Esa subjetividad de Sasha suscita la duración y las dimensiones temporales. Duración y dimensiones que, más que acontecidas, son vividas. Tan densa y viscosa es esa proyección de las animas (la de Sasha, la de Sofía Andreievna, la del staretz Nectáreo, la de Tolstoi), que termina por coagularse en un tejido que reemplaza, o mejor, ocupa, impregnándolo, el lugar de los espacios reales. Estos, Yasnaya Poliana, Schiókino, Gorbachovo, Shamordinó, Óptima Pústyn, y todos los demás que actúan como lexemas toponímicos, hasta llegar a Astápovo, más que existir realmente, tienen los difusos contornos que les da su memoria. Su memoria de cosas vividas. Por eso, en lugar de sitios concretos, parecen borrosos espejismos. Su consistencia depende de Sasha, que, al evocarlos, los realiza, y al realizarlos, los sitúa, otorgándoles un valor mediatizado por el sentido de las vidas de quienes los ocupan fugazmente.

Con dichos recursos el tiempo, los locales y los personajes son sustraídos de su historicidad, para ser dotados de vida literaria. Una vida donada por la voz de la narradora que cuenta la historia, que es leída, vista en el relato, por el lector. Tolstoi o el arrepentimiento le apuesta a la mejor prosa poética, y gana en ese "golpe de dados". El lector navega en la economía, la transparencia, la liviandad, y por encima de todo, en la pobreza de un lenguaje, que, precisamente por pobre en su carencia de artificios y malabares, accede a la riqueza del arte. El "arte pobre" del que hablara Borges en su "Arte poética". En eso radica la fortaleza del relato de esta novela. Gracias a ella el León Tolstoi histórico es trascendido. No creo exagerar si digo desplazado por el Tolstoi literario, ique no deja de ser el primero! ¿No ocurre lo mismo con el Adriano de Maguerite Yourcenar y con el Julio César de Thornton Wilder? De no ser así, no habría creación, novela, sino simple re-creación: biografía. Lo dicho para León Tolstoi aplica para los demás personajes, todos históricos también, y para los topos.

Paso ahora a proponer una inferencia que re-una lo dicho antes, con el análisis de por qué la expresión: "alegoría de la existencia", que forma parte del título. Es un conocimiento legitimado la consideración de lo alegórico como la significación de algo en forma simbólica. Como en el título se da por sentado el valor alegórico de la novela de que me ocupo, es pertinente la pregunta: ¿qué es lo significado? En otras palabras: ¿qué se alegoriza? La respuesta también está en el título: 
"la existencia". Planteada en términos restrictivos alude, en primera instancia, a la de León Tolstoi. Pero extensiva y genéricamente, a la tuya, a la de ella, a la de aquél. A la mía. Y es la existencia, no la vida. No hay tiempo ni espacio para diferenciaciones. La existencia en Tolstoi o el arrepentimiento tiene la forma del motivo del viaje, aun cuando sea breve su decurso. Ya lo dije: es apenas un itinerario. Pero no por eso deja de ser la puesta en micro de lo que en macro son los largos y numerosos años de un prolongado acontecer.

La existencia literaria que nos revela los últimos días de la vida de León Tolstoi está comprendida entre los dos extremos que determinan la de cualquier ser humano: el nacimiento y la muerte. El capítulo primero, "Yasanaya Poliana: la partida", alegoriza el nacimiento. Nacer, empezar a vivir, también es partir... ¿Hacia dónde? Hacia la muerte; hacia Astápovo, en la novela, "la estación de las nubes". Los dos extremos se re-unen, la cabeza mordiendo la cola. Como el ouroboros, el animal imaginario emblemático del devenir, de la circularidad del tiempo eviterno. Yasnaya Poliana, la propiedad feudal, la tierra, el origen de la vida que dará paso a la existencia de León Tolstoi; Astápovo, la estación del ferrocarril, el medio de transporte elegido, que se desplaza sobre carrileras que conducen a las nubes, símbolo ascensional de lo elevado, lo gaseoso e infirme, lo más lábil de todo lo que existe.

De la tierra (Yasnaya Poliana), ¿hacia dónde? Decir hacia el cielo es trivializar la alegoría. Hacia "las nubes”, que son, ¿alegoría de qué? Aventurar una respuesta podría conducir riesgosamente a la destrucción del misterio, al inútil desciframiento de una cifra que se resiste a ser explicada. ¿Acaso el verdadero sentido no es la ausencia de sentido? ¿Lo que los académicos llaman el "sentido vacío”? Hagámosle honor a esta hermosa tesis. Dejemos a Hernán Estupiñán el no despreciable mérito de haber cifrado un enigma que no puede ni debe revelarse desde -y en- el relato. En él está velada alegóricamente la existencia de Tolstoi. Des-velar, la alegoría construida por la imaginación espiritual del escritor es trabajo de los lectores. Para lograrlo es imperativo que des-oculten (aletheia) el acontecer de la verdad que impregna cada página de la novela, renovando conceptualmente, no sólo la percepción que hubieran podido tener del escritor ruso, sino también sus visiones de mundo personales. Eso ocurre cuando la lectura es asumida como una vivencia. Sólo así deviene en puerta abierta hacia una mejor forma de ser. De ninguna manera en sentido moral, sino cognitivo.

Pero falta algo. Omitirlo sería una injusticia con el relato. La novela tiene doce capítulos de los cuales siete tienen el lexema estaciones. 
Así: "del miedo y la espera", "de la vanagloria", "del retorno y la soberbia", "de las nubes y de los recuerdos" (véase la relación entre lo inconsútil de ambos sustantivos); "del descenso", "de la convulsión", y "de las nubes"... "El arrepentimiento" buscado, asumido, ¿alcanzado? por Tolstoi se encuentra aludido e indiciado alegóricamente en esas titulaciones. Ellas son las marcas que señalizan el derrotero del sufrimiento de un hombre que puede ser cualquier hombre, llámese León o Jesús. Un calvario con sus estaciones, que, en el caso de Tolstoi, conducen de su hybris de conde a su némesis de mujik intencional, en la modalidad -Némesis era una diosa que se transformaba- de arrepentimiento. 